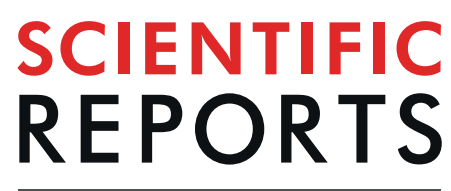

natureresearch

\title{
OPEN Temporal-spatial trends in potentially toxic trace element pollution in farmland soil in the major grain-producing regions of China
}

\author{
Erping Shang $\mathbb{1}^{1,2,3,4}$, Erqi Xu ${ }^{1 *}$, Hongqi Zhang ${ }^{1 *}$ \& Caihong Huang ${ }^{5}$
}

Pollution from potentially toxic trace elements (PTEs) is becoming serious and widespread in farmland soils in China, threatening food security and human health. Few large-scale studies systematically analyzed their temporal-spatial trends over vast spatially elaborate sites. The soil health status of the main grain producing areas was first announced based on a total of 3662 spatially elaborate farmland topsoil sites from the 1980 s to the 2000 s. Nearly $21.5 \%$ of sites were polluted, although only slightly. Pollution from the $\mathrm{Cd}, \mathrm{Ni}, \mathrm{Cu}, \mathrm{Zn}$, and $\mathrm{Hg}$ was more serious. Pollution was more extensive in the south than in the north. There was an increasing trend in the PTE concentrations, especially Cd with a growth of $21-25 \%$, and in the proportion of mixed pollution at the sites (19.3\%), $\mathrm{Cd}(21.5 \%), \mathrm{Pb}(3.6 \%), \mathrm{Zn}$ (5.7\%), $\mathrm{Cu}(7.0 \%)$, and $\mathrm{Hg}$ (3.1\%). Furthermore, temporal variations in severe $\mathrm{Cd}$ pollution and mixedlevel $\mathrm{Hg}$ pollution in the north are severer. This study may provide guidance for policymakers regarding the protection and high-risk area of PTE contamination in the soils.

\footnotetext{
"Potentially toxic trace elements (PTEs)", which are more inclusive and appropriate than the term "heavy met-

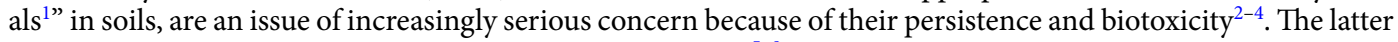
could potentially threaten human health via the food chain ${ }^{5-9}$, especially if these soils are found on arable land and used to grow vegetables and cereals ${ }^{10-14}$. Soil contaminated with PTEs is also becoming an increasingly severe problem because of rapid industrialization and urbanization, and other changes that occurred to agricultural soil in most parts of the world in the last few decades ${ }^{15-18}$. The addition of fertilizers, fungicides, organic amendments, and sewage sludge can have significant detrimental effects ${ }^{19}$ on food safety, ecosystems, and human health ${ }^{20-22}$; these have also been identified as co-factors in many diseases ${ }^{23}$. Numerous recent pollution incidents linked to PTEs (such as "Cadmium rice") in China ${ }^{24,25}$ have led to increasingly strong concern ${ }^{25-29}$. The Law of the People's Republic of China on Soil Pollution Prevention and Control will be implemented on January 1, 2019. China has begun a "war ${ }^{30 "}$ to conquering soil pollution to prevent and control soil heavy metal pollution to protect the safety of agricultural products and human health. How the soil pollution in the main areas, especially the main grain producing areas, is the most concerned issue.

Previous studies focused on the current state of PTE accumulation in the soil in China. Most research on farmland soils was mainly conducted either over small-scale regions such as villages, towns, and counties ${ }^{31,32}$, a selected typical area (i.e., industrial or mining areas) $)^{33,34}$, or with limited cultivated soil sampling points ${ }^{25}$. Some studies also focused on other land use types ${ }^{35-37}$. However, these were insufficient to reveal the overall status of PTE pollution in the agricultural regions of China, where the soil is spatially elaborate soil, without some uncertainties. Furthermore, there are limited reviews of soil PTE pollution in the main grain-producing regions of

${ }^{1}$ Key Laboratory of Land Surface Pattern and Simulation, Institute of Geographic Sciences and Natural Resources Research, Chinese Academy of Sciences, Beijing, 100101, China. ${ }^{2}$ Institute of Remote Sensing and Digital Earth, Chinese Academy of Sciences, Beijing, 100094, China. ${ }^{3}$ Aerospace Information Research Institute, Chinese Academy of Sciences, Beijing, 100094, China. ${ }^{4}$ University of Chinese Academy of Sciences, Beijing, 100049, China. ${ }^{5}$ Chinese Research Academy of Environmental Science, Beijing, 100012, China. *email: xueq@igsnrr.ac.cn; zhanghq@igsnrr. ac.cn
} 

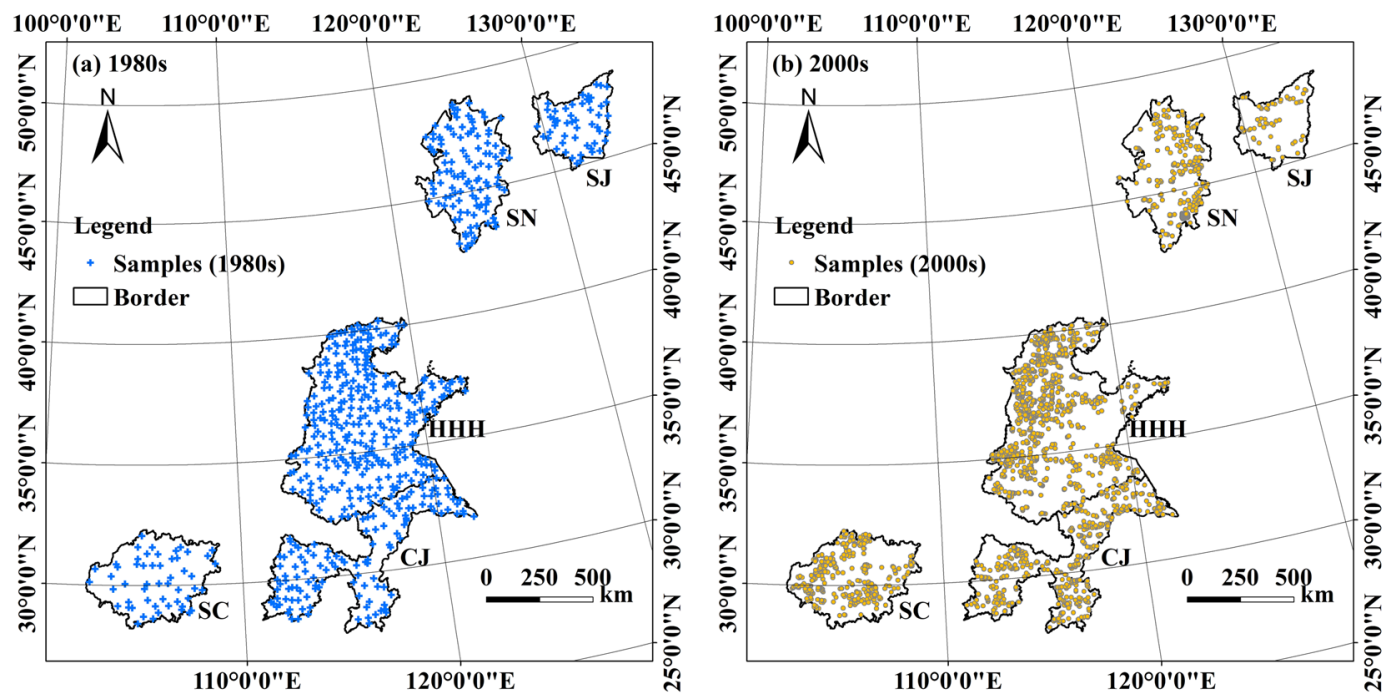

Figure 1. Spatial distribution of the samples in the five major grain-producing regions in China in the 1980s (a) and 2000s (b).

China, which are important to agriculture in the country ${ }^{38}$. An overall evaluation of the main grain-producing regions of China with vast spatially elaborate soils is urgently needed.

However, to date, there has been only limited regional-scale research on temporal trends in PTE contamination in cultivated soils, and little is known about the spatial characteristics. There have also been a few small and medium-scale local studies ${ }^{39-43}$. International researchers have focused on urban soils ${ }^{44}$, mining soils ${ }^{45}$, and industrial soils ${ }^{46}$; less research on cultivated soils. In China, only a few scholars have analyzed the PTEs content in the small and medium-scale scales by obtaining the measured data of soil PTEs in different time periods. For example, Long et al. ${ }^{47}$ analyzed the trend of PTEs content in farmland soil in six periods in Shanghai; Lu et al ${ }^{48}$ comprehensively compared the statistical characteristics and annual trends of PTEs content of three different agricultural land use such as orchards, grain fields and vegetable plots in Beijing from 2005 to 2009; Yang et al. ${ }^{49}$ analyzed the temporal and spatial variation of PTEs in paddy soils polluted by the mining area along the Hengshi River from 2004 to 2012; Song et al. ${ }^{50}$ comparative analysis of PTEs changes in paddy soils in Wenling City, Zhejiang Province in 2006 and 2011. Also, some people used space-time-changing methods or constructed models to analyze trends of soil PTEs content. For example, $\mathrm{Hao}^{51}$ analyzed the PTEs in farmland soils in Cixi for 1000 years according to the time series and mass balance theory. Nevertheless, regional temporal trends of PTEs in the soil environment are very important for environmental risk management ${ }^{52}$ as they can help decision-makers better understand target pollutants and thus make more informed environmental management decisions ${ }^{40}$ related to human health. The lack of a long-term monitoring network means that field surveys and retrospective analyses of published investigations of PTE concentrations are valuable methods with which to comprehensively reveal regional-scale temporal trends in PTE concentrations in cultivated soils and that these can provide deeper insights into environmental behaviors of pollutants than individual field surveys can. However, such research on PTE concentrations in farmland soil in the main grain-producing regions of China is not available.

The Five Main Grain-producing Regions (FMGPRs) of China, namely the Sanjiang Plain (SJ), Songnen Plain (SN), Yangtze River Middle and Jianghuai Plains (CJ), Huang-Huai-Hai Plain (HHH), and Sichuan Basin (SC), comprise more than $60 \%$ of the total cropland area in China and produce nearly $70 \%$ of the food consumed in the country (http://www.zzys.moa.gov.cn). PTE pollution in these regions would pose a threat to the quality and safety of basic and processed agricultural products and human health throughout China and around the world. Therefore, it is necessary to assess the temporal trends of PTEs in the agricultural soils of the FMGPRs. The main objectives of this study were to 1) determine the current status of PTEs in vast, spatially elaborate farmland topsoil over a large scale in the FMGPRs using the single factor index and revised comprehensive pollution index methods, 2) assess their temporal trends, from the 1980 s to the 2000s, at the site- and grid-scale, and 3) to provide guidance for the policymakers regarding environmental management and the reduction and restriction of areas of high-risk soils for future food security and human health.

\section{Material and Methods}

Sample collection and analysis. This study systematically reviewed several studies on soil PTE concentrations in the FMGPRs of China. Of these, the SJ, SN, and HHH are in northern grain-producing regions (NGPRs) while the CJ and SC are in the southern grain-producing regions (SGPRs) (Supplementary Text S1).

A total of 3,662 spatially elaborate farmland topsoil samples were collected in the FMGPRs from the 1980s to the 2000s (Fig. 1). Among them, 656 samples for the period 1982-1990 were obtained by digitizing graded point site maps of $\mathrm{Cd}, \mathrm{Pb}, \mathrm{As}, \mathrm{Ni}, \mathrm{Cu}, \mathrm{Zn}, \mathrm{Cr}$, and $\mathrm{Hg}$ from "The Atlas of Soil Environmental Background Values

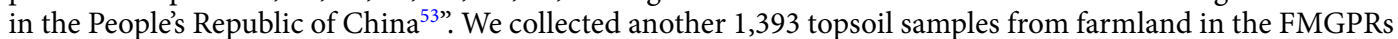
from 2013-2014, and a further 1,613 total samples were derived from the 398 papers published in the 2000s 
(Supplementary Table A1) on the China National Knowledge Infrastructure (CNKI) and Web of Science. The studies reviewed met the following criteria: (1) keywords included "soil," "heavy metal," "PTE," "agriculture," "farmland," "China," and the names of the provinces that make up the FMGPRs, (2) dates between 2000 and 2017, (3) data from field surveys of the targeted heavy metals in farmland topsoil, (4) content and geographical distributions of the target PTEs were obtained directly or through the calculation. Data from humanities and social science journals and soil from industrial and urban land, construction sites, parkland, water bodies, and sediments, were excluded.

We assumed that data from 2000-2017 and 1982-1990 were derived from the same period, termed the "2000s" and "1980s", respectively. As these sites were found across every province and city in the FMGPRs (except $\mathrm{SJ})$, the analysis is relatively comprehensive and provides a large-scale assessment by combining the data from previous papers.

Physical analysis. For the samples from the reviewed studies, soils at each sampling site were collected in three or five cores $(0-20 \mathrm{~cm}$ depth or $0-15 \mathrm{~cm}$ depth) using a bamboo spade, stainless steel spade, or plastic scoop and packed into a single kraft bag or plastic packages using random or uniform sampling methods. While 656 soil samples from the 1980s were spread on a plastic sheet via uniform sampling methods. We collected a mixture of five sub-samples $(0-20 \mathrm{~cm}$ depth) into plastic packages using a plastic scoop. Random sampling methods were used in the areas with a small number of sampling points or no sites, according to the published literature, to fully cover the main cultivated areas in the FMGPRs. In the laboratory, all soil samples were air-dried, ground, and sieved (through $2 \mathrm{~mm}$ mesh) before chemical analysis. The $\mathrm{pH}$ of a portion of each soil sample was also measured. The remaining soil was then passed through a 100 mesh nylon sieve (150 mesh nylon sieve in the 1980s) to analyze the PTE content.

Chemical analysis. In all the studies we reviewed and field surveys we conducted, the total concentrations of PTEs in soils were analyzed by digesting the samples usually using a concentrated mixed acid, such as $\mathrm{HNO}_{3}-\mathrm{HClO}_{4}-\mathrm{HF}$, or $\mathrm{HCl}-\mathrm{HNO}_{3}-\mathrm{HClO}_{4}-\mathrm{HF}$, or aqua regia $\left(\mathrm{HNO}_{3}-\mathrm{HCL}\right)$ and so on. They are all listed in the international standards and national standards, the PTEs contents in soil by them were compatible with the quality control range. A more detailed description of these procedures can be found in the paper ${ }^{54}$. The soil PTEs were then determined using various methods (i.e., ICP-MS, ICPAES, ICP-OES, CV-AAS, AAS, XFS, or XRF), which are accepted by the scientific community and widely used ${ }^{40,55}$. These methods were applied using strict quality control and assurance procedures. Therefore, the combination of published studies and field surveys were generally valid.

Quality control and assurance. Quality control and assurance of analytical accuracy were guaranteed for all samples. Among them, geochemical reference materials (i.e., ESS and GSS) were used mainly for data from the reviewed studies and the 1980s, with relative standard deviations (RSDs) below 15\% for the eight PTEs in the 1980 s and less than $10 \%$ in the 2000s. The analytical procedures used to validate the accuracy of the PTE analysis included careful standardization, procedural blank measurements, and spiked and duplicate samples ${ }^{56}$. For the field survey we conducted, we also used GSS as analytical quality control and achieved RSDs below $10 \%$ for the eight PTEs. This also indicates that combining the published studies and field surveys were also valid in general.

Pollution assessment. Pollution assessment for individual PTEs. Single pollution indexes can be used to rank contamination levels. The pollution index $(P I)$ used herein ${ }^{57,58}$ is defined as follows:

$$
P_{i}=C_{i} / S_{i},
$$

Where $P_{i} C_{i}$, and $S_{i}$ are the single pollution index, measured value $\left(\mathrm{mg} \cdot \mathrm{kg}^{-1}\right)$, and evaluation standard $\left(\mathrm{mg} \cdot \mathrm{kg}^{-1}\right)$ of PTE $i$ for the given situation. The Grade II values (GB15618-1995) which are different from the soil $\mathrm{pH}$ values (Supplementary Table A2) in soils ${ }^{59}$, were used as the standards by which the results of this study were evaluated; this standard is common in China ${ }^{60}$.

The $P I$ was divided into five levels to indicate the degree of contamination: clean $\left(0<P_{i} \leq 0.7\right)$, sub-clean $\left(0.7<P_{i} \leq 1\right)$, slightly polluted $\left(1<P_{i} \leq 2\right)$, moderately polluted $\left(2<P_{i} \leq 3\right)$, or severely polluted $\left(P_{i}>3\right)^{61,62}$.

Pollution assessment for every site. At each sample site, the soil might have been contaminated with one or more PTEs; therefore, there may be multiple PI values greater than 1 . The Nemerow pollution index (NPI) was used, in general, to evaluate the comprehensive pollution level of PTE pollution in the soil ${ }^{63}$. However, in addition to emphasizing the influence of the maximum single pollution index, this study also considered the average concentration $^{64}$. This can produce easily generated, biased assessment results in terms of accurately determining whether or not the PTE at a site exceeded the standard; that is, whether or not it was an "excessive site" (ES). For example, the NPI at one site was 0.98 if the eight PTE PI values were $1.2,0.3,0.6,0.7,0.8,0.5,0.54$, and 0.62 ; however, the NPI would show that this site was clean, since the former ignored the excess elements that existed at this site.

To address this issue, we defined the term "excessive site" (ES) as one from which a sample had PTE PI values greater than 1, the slightly lower pollution limit. The pollution level of an ES was determined by the maximum PI (MPI). The revised comprehensive pollution index can, therefore, be expressed as follows:

$$
M P I=P_{\text {site }}=\max \left(P_{i}\right)
$$

Where $P_{\text {site }}$ is the pollution index of the site and $P_{i}$ is the single pollution index of PTE $i$. We also defined it into five levels: clean $(0<\mathrm{MPI} \leq 0.7)$, sub-clean $(0.7<\mathrm{MPI} \leq 1)$, slightly polluted $(1<\mathrm{MPI} \leq 2)$, moderately polluted 


\begin{tabular}{|l|l|l|l|l|l|l|l|l|}
\hline Properties & Cd & Pb & As & Ni & Cu & Zn & Cr & Hg \\
\hline Sites & 2,784 & 2,889 & 2,137 & 1,664 & 2,498 & 2,150 & 2,510 & 2,152 \\
\hline 10th & 0.073 & 16.34 & 5.04 & 19.29 & 14.46 & 46.00 & 35.60 & 0.025 \\
\hline 25th & 0.111 & 20.66 & 6.95 & 23.97 & 19.36 & 58.74 & 51.90 & 0.034 \\
\hline 50 th & 0.159 & 24.97 & 8.87 & 27.76 & 23.94 & 71.70 & 62.30 & 0.052 \\
\hline 75th & 0.266 & 33.85 & 10.80 & 32.87 & 29.67 & 90.32 & 72.51 & 0.090 \\
\hline 90th & 0.538 & 50.00 & 13.17 & 41.25 & 40.78 & 123.59 & 86.21 & 0.161 \\
\hline Mean & 0.329 & 29.36 & 9.74 & 29.43 & 26.31 & 84.43 & 62.75 & 0.104 \\
\hline SD & 0.691 & 16.13 & 10.09 & 10.84 & 13.54 & 70.45 & 22.63 & 0.239 \\
\hline Mean* & 0.537 & 30.69 & 11.62 & 32.56 & 28.07 & 104.92 & 65.40 & 0.207 \\
\hline SD* & 5.61 & 27.97 & 91.14 & 59.77 & 32.68 & 381.29 & 44.60 & 3.03 \\
\hline Skewness & 24.63 & 13.23 & 45.47 & 18.54 & 14.78 & 22.98 & 11.60 & 19.55 \\
\hline Kurtosis & 696.70 & 283.06 & 2089.65 & 361.57 & 280.95 & 612.62 & 214.61 & 394.75 \\
\hline CV (\%) & 930 & 91 & 785 & 183 & 116 & 363 & 68 & 1144 \\
\hline NES_C & 2460 & 1684 & 842 & 1176 & 1695 & 1252 & 1602 & 1488 \\
\hline NES_P & 2354 & 1556 & 513 & 719 & 1466 & 1119 & 1061 & 1608 \\
\hline BV & 0.097 & 26 & 11.2 & 26.9 & 22.6 & 74.2 & 61 & 0.065 \\
\hline
\end{tabular}

Table 1. Summary statistics of the concentrations of PTEs in Chinese farmland soils in the 2000s $\left(\mathrm{mg}^{\mathrm{kg}} \mathrm{kg}^{-1}\right)$. Mean*: mean with abnormal values; SD: standard deviation; SD*: standard deviation with abnormal values; CV: coefficients of variation; NES_C: numbers of sampling sites with concentration exceeded the background values in the whole China; NES_P: numbers of sampling sites with concentration exceeded the background values in their provinces; BV: background values in China. The abnormal values are a non-measurement error. That is also a true reflection of the pollution status of PTEs in the soil, indicating that the soil has a very high level of PTEs.

$(2<\mathrm{MPI} \leq 3)$, or severely polluted (MPI $>3)$. The ES percentage refers to the proportion of total sample sites meeting the ES criteria ${ }^{60}$.

Statistical analysis and spatial mapping. The data are presented as the mean \pm standard deviation (SD). Statistical analysis was performed using SPSS 18.0. The $10^{\text {th }}, 25^{\text {th }}, 50^{\text {th }}, 75^{\text {th }}$, and $90^{\text {th }}$ percentiles, mean, SD, and coefficient of variation $(\mathrm{CV})$ of the PTE concentrations was calculated. The normality of the data was evaluated in SPSS, and the standardized skewness and kurtosis values indicate significant departures from normality for all eight PTEs (Table 1). Furthermore, the soil PTE content in the 1980 s were classified into eight grades $(5 \%, 10 \%$, $25 \%, 50 \%, 75 \%, 90 \%, 95 \%, 100 \%$ ) (Supplementary Table A3) using the unified numeral grading method. The soil PTE content in the 2000s was also classified using the same system to allow the evaluation of spatio-temporal changes in the PTEs between the 1980s and the 2000s. Meanwhile, the original eight grades were divided into the categories "clean", "mixed pollution", and "serious pollution". Mixed pollution mainly refers to a combination of mild and moderate pollution. Serious pollution is that most of the content of PTEs in the samples is far more than 3 times the standard value. Their concentration range can be seen in Supplementary Tables A3 and A4.

The spatial distributions of the PTEs in the 1980s and 2000s were mapped using the inverse distance weighted (IDW) method and at the point scale in ArcGIS 10.1. The distance between the interpolation point and the sample point was used to weight the average, such that shorter distances conferred a greater weight. The predicted value was equal to the measured value at the sample point, and the original maximum and minimum values were not changed. In addition, the high spatial heterogeneity in the agricultural soils, farming methods, pollution sources, and other factors induces high spatial heterogeneity in the soil type of the FMGPRs. This introduces uncertainties into any spatial distribution maps produced via spatial interpolation methods. Therefore, we also focus on an overall analysis of the percentages of sites with the various pollution levels and different point scale PTE pollution levels within the total study region during the 1980s and 2000s to better explore trends in PTEs levels.

\section{Results and Discussion}

PTE concentrations in soils. Descriptive statistics for PTE concentrations in soils from the FMGPRs in China are presented with the relevant geochemical background values (BVs) ${ }^{65}$ in Table 1 . The arithmetic means of Cd (0.329 \pm 0.691$), \mathrm{Pb}(29.36 \pm 16.13)$, As (9.74 \pm 10.09$), \mathrm{Ni}(29.34 \pm 10.84), \mathrm{Cu}(26.31 \pm 13.54), \mathrm{Zn}$ (84.43 \pm 70.45$), \mathrm{Cr}(62.75 \pm 22.63)$, and $\mathrm{Hg}(0.104 \pm 0.239)$ (all units in $\left.\mathrm{mg} \cdot \mathrm{kg}^{-1}\right)$ are higher than the corresponding local BVs. The median concentrations of Cd (0.159 versus BV limit of 0.097$)$, Ni (27.76 versus BV limit of 26.9), $\mathrm{Cu}$ (23.94 versus BV limit of 22.6), and $\mathrm{Cr}$ (62.30 versus BV limit of 61) are higher than the background values in China (Table 1) (all units in $\mathrm{mg} \cdot \mathrm{kg}^{-1}$ ). This suggests that in at least half of the farmland soil samples, these four PTEs come from anthropogenic sources as well as from the parent rock. On the other hand, the median concentrations of $\mathrm{Pb}, \mathrm{As}, \mathrm{Zn}$, and $\mathrm{Hg}$ are slightly below their BV limits. Approximately $84.6 \%$ of the Cd samples and $74.7 \%$ of the $\mathrm{Hg}$ samples surpass their provincial BVs, followed by $\mathrm{Cu}(58.7 \%), \mathrm{Pb}(53.9 \%)$, and $\mathrm{Zn}(52.0 \%)$; $24 \%$ to $43 \%$ of the As, Cr, and Zn samples.

Table 1 also shows significant heterogeneity in the spatial distribution of eight PTEs, which is reflected in the high SDs and CVs (from 68\% to 1144\%). Samples are considered highly variable and dispersed when the $\mathrm{CV}>36 \%{ }^{66}$. The kurtosis values of all eight PTEs are greater than zero, demonstrating that the distributions of the 


\begin{tabular}{|l|l|l|l|l|l|l|l|}
\hline Regions & Sites & $\begin{array}{l}\text { Numbers } \\
\text { of ES }\end{array}$ & $\begin{array}{l}\text { Percentage } \\
\text { of ES (\%) }\end{array}$ & $\begin{array}{l}\text { Slight } \\
\text { pollution (\%) }\end{array}$ & $\begin{array}{l}\text { Moderate } \\
\text { pollution (\%) }\end{array}$ & $\begin{array}{l}\text { Severe } \\
\text { pollution (\%) }\end{array}$ & $\begin{array}{l}\text { Percentage of exceeds the risk screening } \\
\text { value (GB 15618-2018) (\%) }\end{array}$ \\
\hline SJ & 60 & 1 & 1.7 & 0.0 & 1.7 & 0.0 & 1.7 \\
\hline SN & 353 & 33 & 9.4 & 2 & 4 & 3.4 & 10.0 \\
\hline CJ & 731 & 224 & 30.6 & 21.6 & 1.9 & 7.1 & 30.4 \\
\hline HHH & 1350 & 165 & 12.2 & 5.8 & 1.3 & 5.1 & 11.1 \\
\hline SC & 512 & 223 & 43.6 & 34.6 & 5.5 & 3.5 & 33.6 \\
\hline Whole & 3006 & 646 & 21.5 & 14.0 & 2.5 & 5.0 & 20.1 \\
\hline
\end{tabular}

Table 2. Percentages of potentially toxic trace elements in farmland soils, based on class distributions used in the pollution assessment and percentage of excessively polluted sites in the 2000s.

concentrations of these elements in the samples are narrower than a normal distribution. Furthermore, kurtosis and skewness values for typical PTEs (Cd, As, $\mathrm{Zn}$, and $\mathrm{Hg}$ ) are higher than those for other PTEs indicating the existence of highly contaminated areas.

Distribution and pollution assessment. Comparative analysis of excessive site (ES) percentages. Of the 3006 soil samples analyzed in the 2000s, $21.5 \%$ exceeded the GB15618-1995 environmental quality standard ${ }^{59}$, and $20.1 \%$ exceeded the risk screening value (GB 15618-2018). They are slightly higher than the ES percentage (19.4\% of the cultivated land) described in the National Bulletin on Soil Pollution Status in $2014^{60}$. It can be seen that the results of the new standard (GB 15618-2018) are slightly lower than the old standard (GB15618-1995), but the difference is small. And because GB15618-1995 standard can be better compared with the published literature of the peers, especially the officially published authoritative reports ${ }^{60}$, which all used GB15618-1995, and the main evaluation criteria are also based on GB15618-1995. The dominant ES pollution level in the samples was "Slightly polluted (14.0\%); the others were "moderately polluted" (2.5\%) and "severely polluted" (5.0\%) (Table 2).

The soil PTE pollution is heavier in the SGPRs than in the NGPRs (Fig. 2, Table 2). The SC region features the highest ES percentages (43.6\%), followed by CJ (30.6\%), HHH (12.2\%), SN (9.4\%), and SJ (1.7\%). Moreover, the "slightly polluted" ES percentages are larger in the SC (34.6\%) and CJ (21.6\%) than in the other regions, each of which has less than $6 \%$.

The CJ region had the most severely polluted samples (7.1\%). These were collected in cities in the north (i.e., Yangzhou, Chuzhou, Hefei, and Huaian), west and southwest (Yiyang, Changde, and Xiaogan), and southwest along the border of Nanchang. The HHH possessed the second-highest severe pollution ES percentages (5.1\%); these samples were collected near northern, central, and southeastern cities including Beijing, Tianjin, Baoding, Hengshui, Jinan, Xinxiang, Zhengzhou, Jiaozuo, Xuzhou, Lianyungang, Bengbu, Huaian, and Nanjing.

The SC and SN have severely polluted ES percentages of 3.5\% and 3.4\%, respectively. The ESs in the SC are primarily distributed on its western margins, including Chengdu, Deyang, and YảAn; the northern city of Mianyang; and the southeastern city of Chongqing. The severely polluted ESs in the SN are located largely in the east and south, including Wangkui County, Zhaodong, Yushu, Haerbin, Jiutai, and Changtu. There were no severely polluted ESs in the SJ).

Overall, the highest ES percentages were found in the SC. The highest ES percentages, indicating severe pollution, were found in the CJ region followed by the HHH. Most samples from the SJ and SN can be considered clean.

Comparative analysis of major PTEs using the Pollution Index. The PI values of the eight PTEs vary widely, ranging from clean to severely contaminated (Supplementary Fig. A1, Supplementary Table A5). The major pollutants are $\mathrm{Cd}, \mathrm{Ni}, \mathrm{Cu}, \mathrm{Zn}$, and $\mathrm{Hg} ; 17.4 \%, 8.4 \%, 4.0 \%, 2.8 \%$, and $2.6 \%$ of the PI values of these pollutants are higher than 1 ; less than $1 \%$ of other PTEs are $>1$. PTE contamination of cultivated land is more concentrated in the SGPRs. Moreover, slightly polluted areas account for $60 \%$ of the $\mathrm{Cd}, \mathrm{Zn}$, and $\mathrm{Hg}$ measurements; $85 \%$ of the Cu samples; and $92 \%$ of the Ni samples.

The agricultural soils in the FMGPRs are contaminated by Cd; it was the dominant pollutant in all regions, with $P I$ values above the slightly polluted level in $17.4 \%$ of the samples. The percentage of Cd PI values above the slightly polluted level varies widely, ranging from $1.7 \%$ in the SJ to $34.9 \%$ in the SC. The SC features the highest proportion of slightly polluted sites (27.1\%); these were located in the western cities of Chengdu, Deyang, and YaAAn. Meanwhile, the eastern city of Chongqing had the highest number of severely polluted sites (2.9\%) (Fig. 3). In the CJ, which had the highest Cd PI values, approximately $21.9 \%$ of the samples had Cd PI values greater than 1. The sites with severe Cd pollution levels (5.2\%) were located in the northern cities of Yangzhou, Nanjing, Chuzhou, and Huaian; the western cities of Xiaogan and Changde; Yiyang in the southwest; and Nanchang in the south. The HHH featured the third-highest percentage of Cd pollution (10.8\%). Samples showing severe pollution came predominantly from Nanjing, Yangzhou, Xinxiang, Jinan, Tianjin, Hengshui, Beijing, Xuzhou, Huaian, Zhenjiang, and Bengbu. The SN featured a Cd pollution percentage of $9.8 \%$. Severely polluted samples (3.8\%) were distributed in the northeastern and southern SN, including Wangkui County, Harbin, and Zhaodong.

Nickel and $\mathrm{Cu}$ pollution are not as extensive as that of $\mathrm{Cd} ; 8.4 \%$ of the Ni samples and $4.0 \%$ of the Cu samples indicate more than slight pollution levels. Less than $3 \%$ of $\mathrm{Ni}$ samples and $1 \%$ of $\mathrm{Cu}$ samples in the NGPRs were more than slightly polluted, and these figures are above $16 \%$ for $\mathrm{Ni}$ and $8 \%$ for $\mathrm{Cu}$ in the SGPRs. However, there were extreme $\mathrm{Ni}$ values in the $\mathrm{HHH}$; this was unlike $\mathrm{Cu}$, where the extreme values were located in the $\mathrm{CJ}$ and SC. In the CJ and SC, $16-31 \%$ of the Ni samples and 8-9\% of the Cu samples featured more than slight pollution; this 
(a) $\mathbf{S J}$

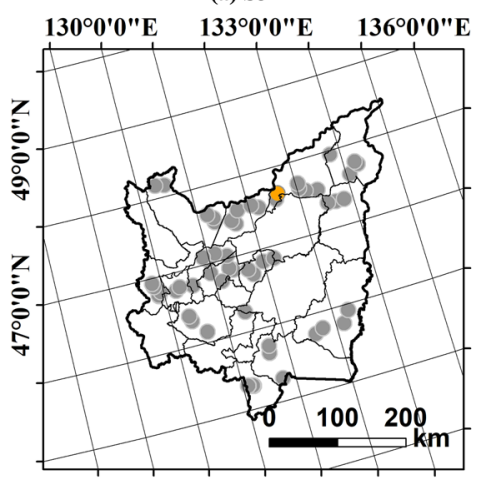

(d) CJ

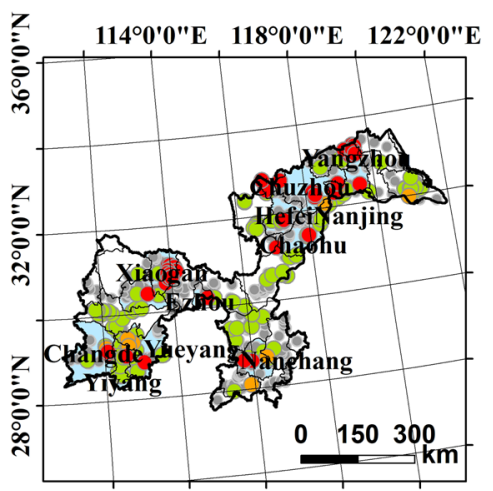

(b) $\mathrm{SN}$

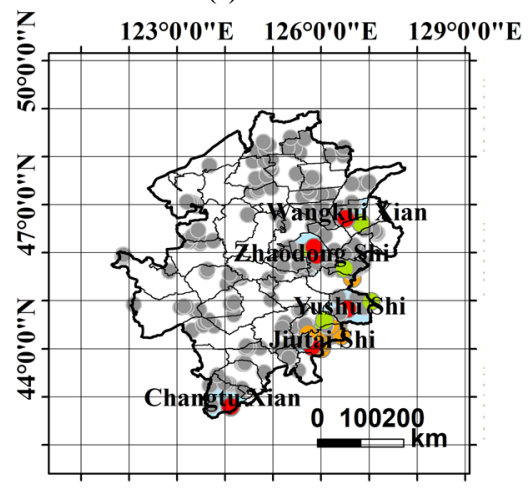

(e) $\mathrm{SC}$

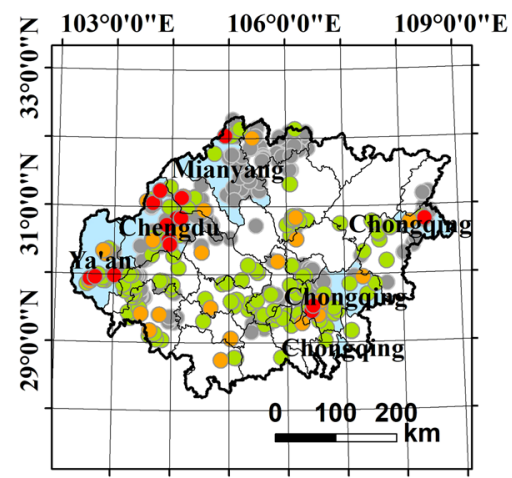

(C) $\mathrm{HHH}$

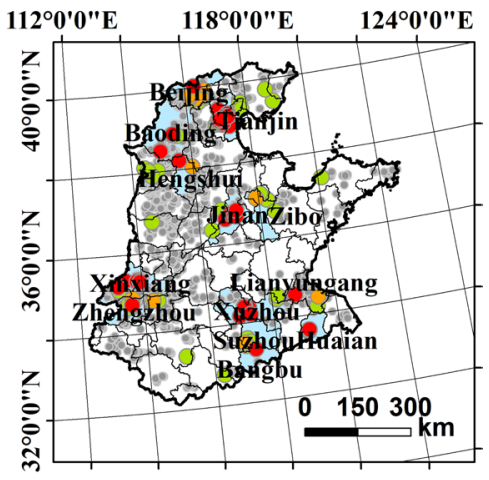

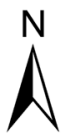

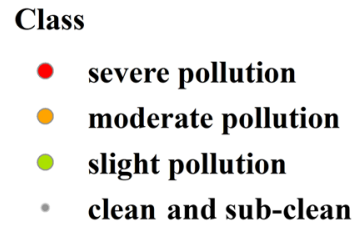

Figure 2. Spatial distribution of the pollution levels of potentially toxic trace elements in the farmland soils in the five major grain-producing regions in China. (a) SJ; (b) SN; (c) $\mathrm{HHH}$; (d) CJ; (e) SC.

number was less than $3 \%$ for $\mathrm{Ni}$ and $\mathrm{Cu}$ in the other study regions. However, $\mathrm{Ni}$ and $\mathrm{Cu}$ contamination were not severe in general. Less than $8 \%$ of the polluted samples were moderately polluted, and less than $14 \%$ were severely polluted. The distributions of $\mathrm{Ni}$ and $\mathrm{Cu}$ in the SC were distinctly different from those in the CJ. In the CJ, the more than slightly polluted samples came chiefly from the north and southwest. However, small pockets of severe $\mathrm{Ni}$ pollution $(0.3 \%)$ were found in the central city of Ezhou. In a line of cities from southwest to northeast, $1.0 \%$ of sites featured $\mathrm{Cu}$ pollution classified severely polluted above. In the $\mathrm{SC}, \mathrm{Ni}$, and $\mathrm{Cu}$ pollution occurred mainly in the western and southern areas. A small number of moderately polluted samples were found in Neijiang and Zigong, while severe pollution was recorded in samples from Chengdu and Chongqing, which surround industrial and mining regions.

In the FMGPRs, $2.8 \%$ and $2.6 \%$ of the samples of $\mathrm{Zn}$ and $\mathrm{Hg}$, respectively, were more than slightly polluted. The highest $\mathrm{Zn}$ and $\mathrm{Hg}$ PI values were both located in the CJ, which was sampled most heavily. Accordingly, $4.6 \%$ of the $\mathrm{Zn}$ samples and 3.0\% of the $\mathrm{Hg}$ samples from this region featured more than slight pollution. In the $\mathrm{HHH}$ and SC, $2-3 \%$ of the soil samples had an excess of $\mathrm{Zn}$ and $\mathrm{Hg}$ were; this value was less than $0.5 \%$ in the SN and SJ. Slightly polluted samples were dominant. In the CJ region, the samples with the highest $\mathrm{Zn}$ contamination were found near cities in the southwest and northeast, particularly in Yangzhou and Yueyang. Conversely, Hg pollution occurred largely in the northern city of Yangzhou, the western city of Tianmen, and the southwestern city of Changde. In the $\mathrm{HHH}$ region, samples with $\mathrm{Zn}$ pollution were chiefly from near the northern cities, along a line from northwest to southeast, notably including Beijing, Baoding, and Xinxiang, which had the highest levels of $\mathrm{Zn}$ contamination. Small pockets of severe $\mathrm{Hg}$ pollution occurred in Baoding, Xinxiang, Jinan, and Xuzhou. In the SC, Zn pollution was concentrated in the northwestern and south-central cities, especially Chongqing. Hg pollution tended to be higher in the northwestern and central cities, especially Mianyang and Chengdu in the former regions.

Temporal and spatial trends. Trends of concentrations of PTEs in soils. The PTE concentrations in cultivated soils in the FMGPRs increased, in general, between the 1980s and the 2000s (Fig. 4). The proportion of low PTE concentrations decreased while the proportion of high PTE concentrations is increasing.

The concentrations of $\mathrm{Cd}, \mathrm{Pb}, \mathrm{Zn}, \mathrm{Cu}$, and $\mathrm{Hg}$ have increased; for $\mathrm{Cd}$, the difference was severe. The proportions of these elements in grades 8 and 9 increased by $25.0 \%, 4.2 \%, 6.1 \%, 3.6 \%$, and 3.1\%, respectively. In the $1980 \mathrm{~s}, 55.5 \%$ of the study area contained $0.08-0.12 \mathrm{mg} \cdot \mathrm{kg}^{-1}$ of $\mathrm{Cd}$, which could be categorized as "clean." However, in the 2000s, most measurements showed Cd contents between $0.12-0.19 \mathrm{mg} \cdot \mathrm{kg}^{-1}$ and $0.27-2 \mathrm{mg} \cdot \mathrm{kg}^{-1}$, and the proportion of $\mathrm{Cd}$ in the mixed pollution range $\left(0.27-2 \mathrm{mg} \cdot \mathrm{kg}^{-1}\right)$ increased from $0.5 \%$ to $24.5 \%$. The changes in $\mathrm{Hg}$ content are similar to those in $\mathrm{Cd}$. $\mathrm{Hg}$ content increased from being predominantly within the 

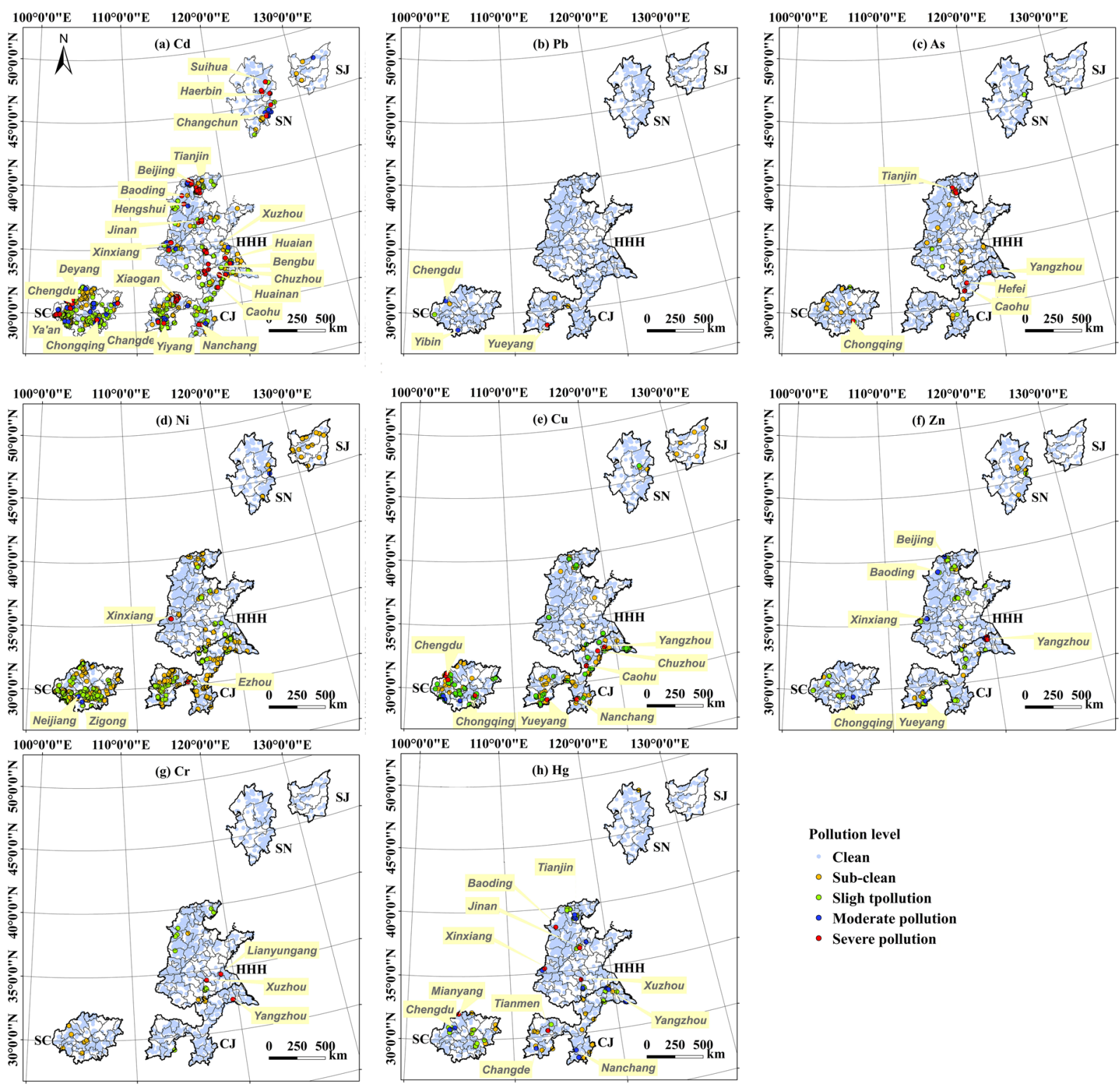

Figure 3. Potentially toxic trace element pollution levels in the five major grain-producing regions in China. (a) $\mathrm{Cd},(\mathbf{b}) \mathrm{Pb},(\mathbf{c}) \mathrm{As},(\mathbf{d}) \mathrm{Ni},(\mathbf{e}) \mathrm{Cu},(\mathbf{f}) \mathrm{Zn},(\mathbf{g}) \mathrm{Cr},(\mathbf{h}) \mathrm{Hg}$.

$0.02-0.04 \mathrm{mg} \cdot \mathrm{kg}^{-1}$ range in the $1980 \mathrm{~s}$ to lying between $0.08-0.15 \mathrm{mg} \cdot \mathrm{kg}^{-1}$ in the $2000 \mathrm{~s}$. The increases in $\mathrm{Pb}, \mathrm{Zn}$, and $\mathrm{Cu}$ were relatively low, the areas affected by grade 8 and 9 pollution increased somewhat (3-6\%); the concentrations of $\mathrm{As}, \mathrm{Ni}$, and $\mathrm{Cr}$ have increased by less than $1 \%$ (Fig. 4).

There are also significant regional differences in the high concentrations (grade 8-9) of $\mathrm{Cd}, \mathrm{Pb}, \mathrm{Zn}, \mathrm{Cu}$, and $\mathrm{Hg}$. The increase in the area of high concentration of Cd (8-9) is the largest in the SC (34.4\%), followed by CJ (21.7\%) and $\mathrm{HHH}(17.7 \%)$. The changes in $\mathrm{Pb}$ and $\mathrm{Cu}$ are similar to those in $\mathrm{Cd}$ and increased more in the SGPRs, which increased by $5.8 \%-13.0 \%$ for $\mathrm{Pb}, 3.0 \%-9.3 \%$ for $\mathrm{Cu}$, while $1.3 \%$ for $\mathrm{Pb}, 3.0$ for $\mathrm{Cu}$ in $\mathrm{HHH}$. However, the increase of $\mathrm{Hg}$ showed the opposite trend, and the highest growth was in $\mathrm{HHH}(6.4 \%)$, and less than $1.5 \%$ in SGPRs.

Trends at the point-scale ES percentages in different regions. For the pollution level, the proportion of sites in the FMGPRs with higher than mixed pollution levels increased from $13.9 \%$ to $33.2 \%$ from the 1980 s to the 2000 s; this was an overall growth of $19.3 \%$ (Fig. 5, Figure A2). Of these increases, the proportions of samples showing mixed and serious pollution levels increased by $16.5 \%$ and $2.8 \%$, respectively. The increases in ES percentage differed by region. In the SJ, PTE pollution tended to vary within the "clean" range over time. However, there was marked variation in the mixed and severe pollution levels in the remaining four regions.

The percentage of ESs above the mixed pollution level increased the most in the SC (29.4\%); it was 1.90 times the growth in the SN, 2.21 times that in the CJ, and 2.25 times that in the HHH. Severe pollution levels saw only 
(a1) $1980 \mathrm{~s} \mathrm{Cd}$

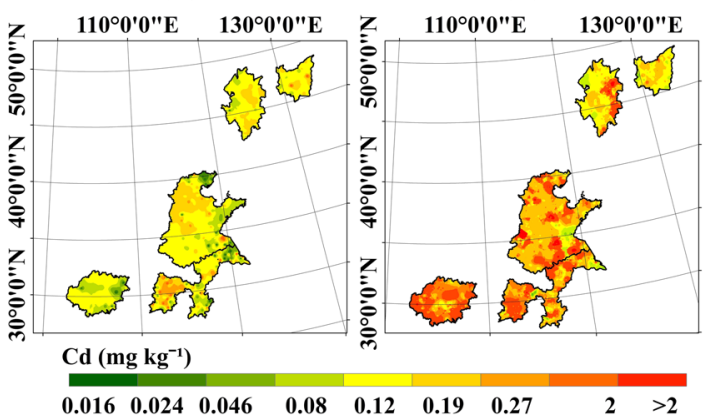

(c1) $1980 \mathrm{~s} \mathrm{As}$

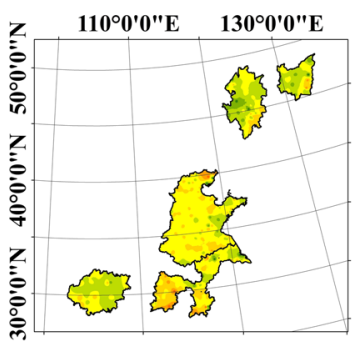

As (mg kg-1)

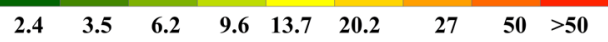

(e1) $1980 \mathrm{~s} \mathrm{Cu}$

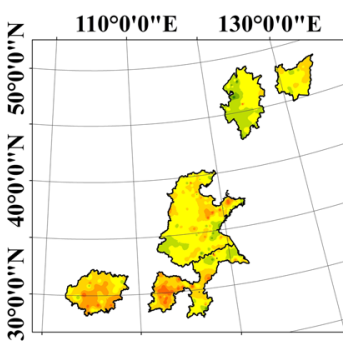

Cu (mg kg-1)$$
6.0
$$

(g1) $1980 \mathrm{~s} \mathrm{Cr}$

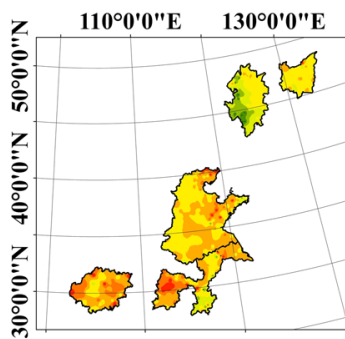

$\mathrm{Cr}\left(\mathrm{mg} \mathrm{kg}{ }^{-1}\right)$

$\begin{array}{llll}17.2 & 23.8 & 40.2 & 57.3\end{array}$ (e2) 2000s Cu

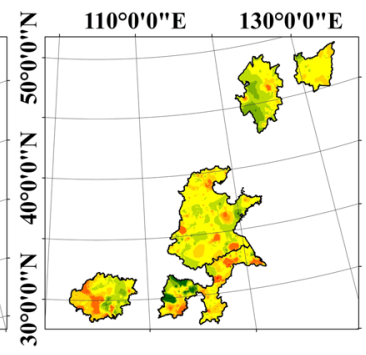

(g2) 2000s Cr

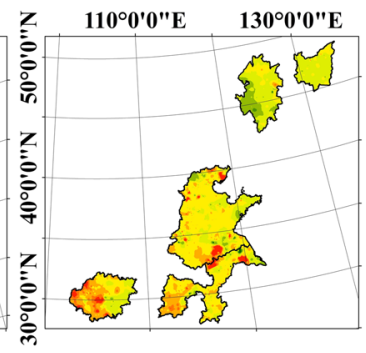

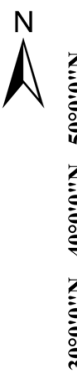
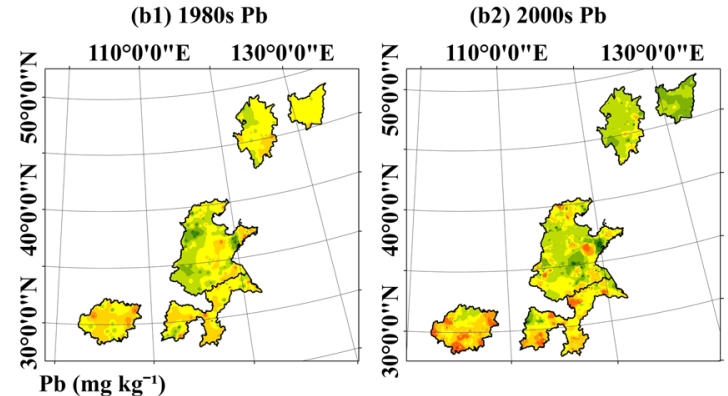

$\begin{array}{lllllllll}10 & 13.5 & 18.5 & 23.9 & 31.1 & 43.8 & 56 & 300 & >300\end{array}$

(d1) $1980 \mathrm{~s} \mathrm{Ni}$

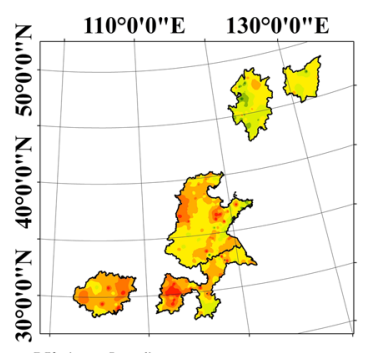

$\mathrm{Ni}\left(\mathrm{mg} \mathrm{kg}^{-1}\right)$

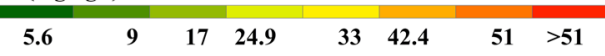

(f1) $1980 \mathrm{~s} \mathrm{Zn}$

(f2) $2000 \mathrm{~s} \mathrm{Zn}$

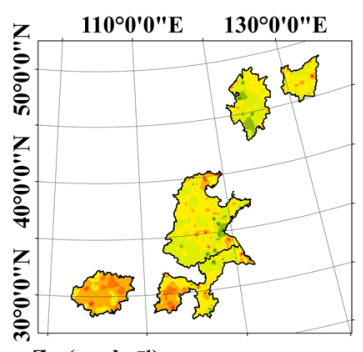

Zn (mg kg-1)

$\begin{array}{lllllll}25 & 34.7 & 50.9 & 67.3 & 88.5 & 116.9 & 142.8>142.8\end{array}$

(h1) $1980 \mathrm{~s} \mathrm{Hg}$

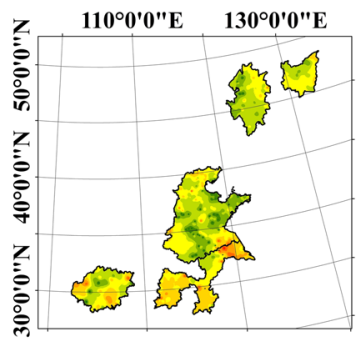

(h2) $2000 \mathrm{~s} \mathrm{Hg}$

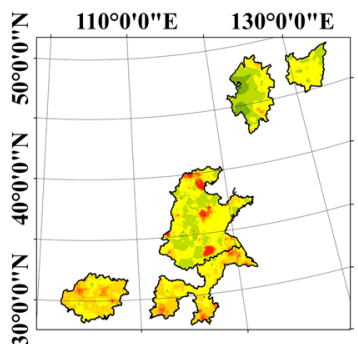

$\mathrm{Hg}\left(\mathrm{mg} \mathrm{kg}^{-1}\right)$

$\begin{array}{lllllllll}0.009 & 0.012 & 0.02 & 0.04 & 0.08 & 0.15 & 0.22 & 0.5 & >0.5\end{array}$

$1,000 \quad 2,000$

Figure 4. Trends in the concentrations of potentially toxic trace elements in the five major grain-producing regions in China from the 1980s to 2000s. (a1) 1980sCd, (a2) 2000sCd, (b1) 1980sPb, (b2) 2000sPb, (c1) 1980s As, (c2) 2000s As, (d1) 1980s Ni, (d2) 2000s Ni, (e1) 1980s Cu, (e2) 2000s Cu, (f1) 1980s Zn, (f2) 2000s Zn, (g1) 1980s Cr, (g2) 2000s Cr, (h1) 1980s Hg, (h2) 2000s Hg.

$\sim 3 \%$ growth in all regions, while the percentage of ESs at the mixed pollution level increased by more than $13 \%$ in all regions except the SJ.

The mixed pollution level increased more in the SGPRs (Fig. 5) than in the NGPRs; the highest increase was in the SC, at $26.3 \%$ this was 1.9 times the growth in the $\mathrm{SN}, 1.6$ times that in the CJ, 2.5 times that in the $\mathrm{HHH}$, and 
(a) Mixed pollution level
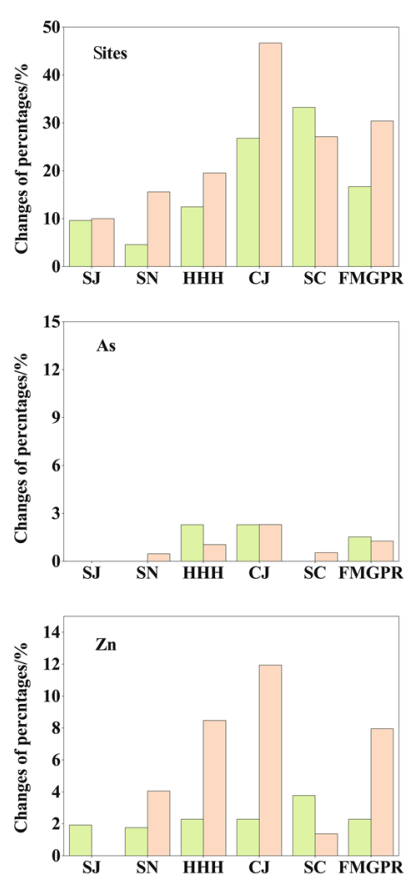

(b) Serious pollution level
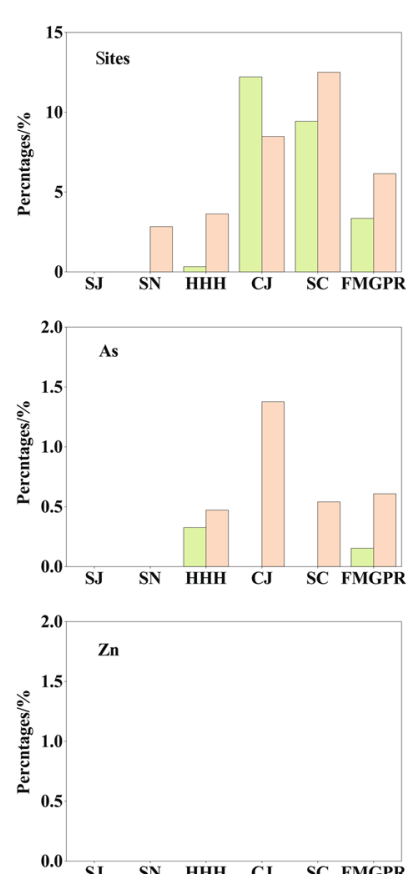

$1980 \mathrm{~s} \longrightarrow 2000 \mathrm{~s}$
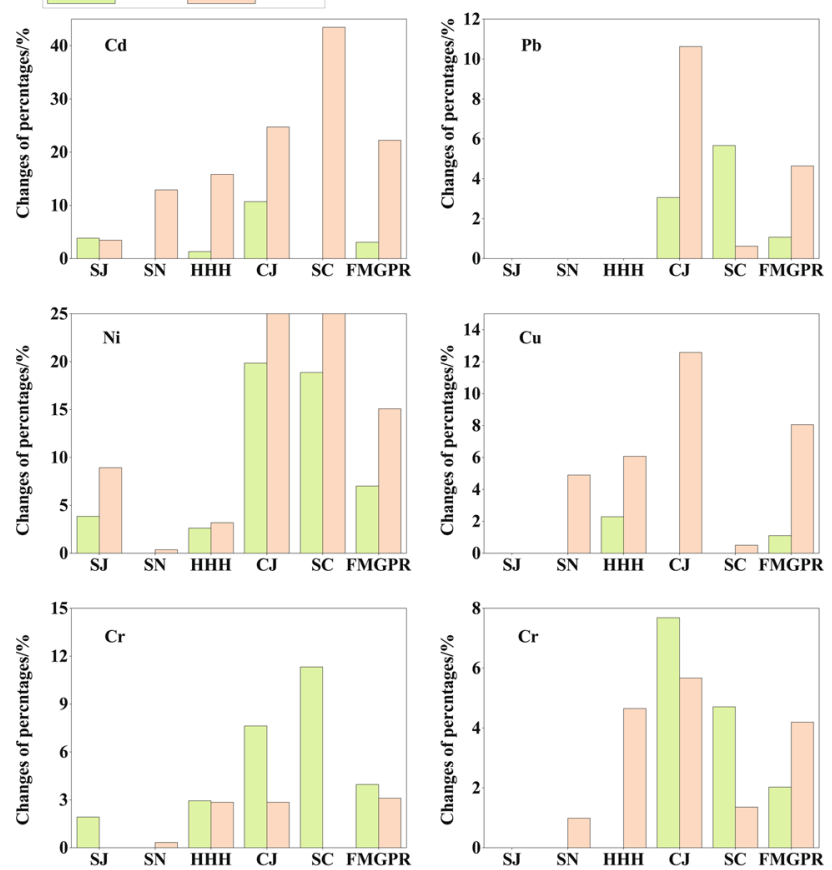
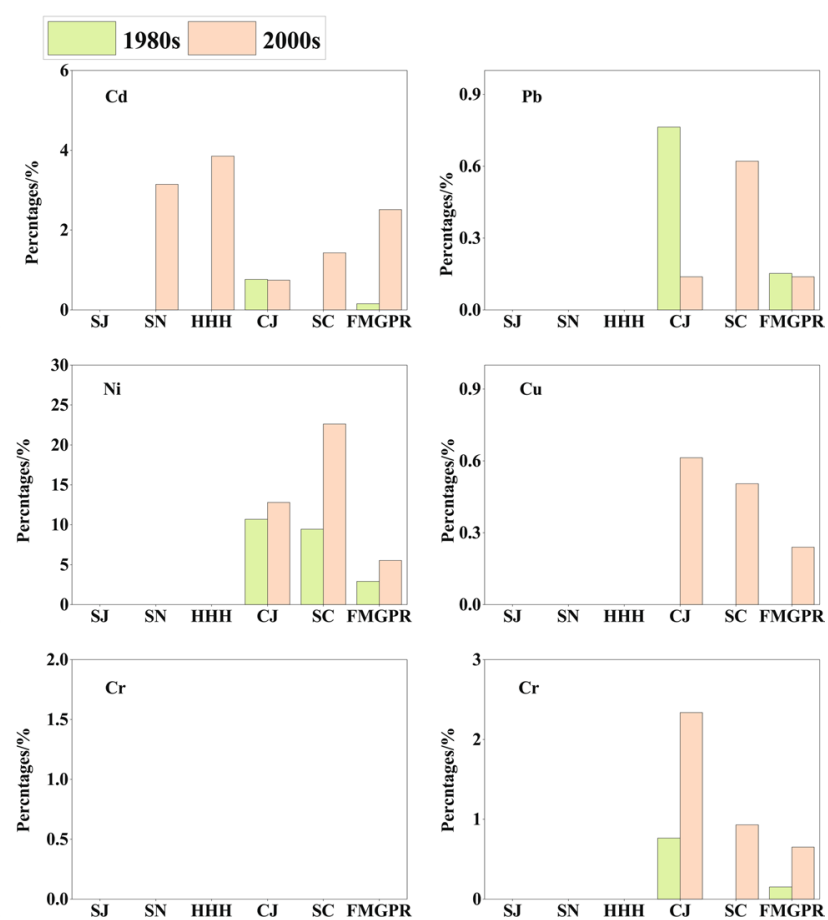

Figure 5. Changes in the percentages of the total sampled sites at the different pollution level in different regions from the 1980 s to the 2000 s.

68.4 times that in the SJ. Seriously polluted samples increased by only $3 \%$ in the SN, HHH, and SC, and no severe pollution was observed in the SJ.

The proportion of clean samples decreased by about $19 \%$. This decrease was the highest in the SC (29.4\%), followed by $16.7 \%$ in the $\mathrm{SN}$ and $13 \%$ in the $\mathrm{HHH}$ and CJ.

Trends in point-scale individual PTEs in different regions. The increases in $\mathrm{Cd}, \mathrm{Pb}, \mathrm{Zn}, \mathrm{Cu}$, and $\mathrm{Hg} \mathrm{PTE}$ contamination was relatively serious; the number of sites contaminated above the mixed pollution level increased by $21.5 \%, 3.6 \%, 5.7 \% .7 .0 \%$, and $3.1 \%$, respectively, for these pollutants (Fig. 5, Figure A3). Furthermore, there 
were more temporal variations in severe Cd pollution and mixed $\mathrm{Hg}$ pollution in the NGPRs than in the SGPRs; the opposite trends were observed for the percentages of $\mathrm{Ni}, \mathrm{Cu}, \mathrm{Zn}$, and $\mathrm{Pb}$ samples at the mixed pollution level.

Cd concentrations have increased markedly. Samples at or above the mixed pollution level increased by $21.5 \%$ overall; mixed and severely polluted samples have increased by $19.2 \%$ and $2.4 \%$, respectively. At the mixed pollution level, the highest increases were observed in the SC (43.5\%), followed by the HHH (14.5\%), CJ (14.0\%), SN $(12.9 \%)$, and SJ $(-0.4 \%)$. However, the increases in measurements of severe pollution were higher in the NGPRs (above 3\%) than in the SGPRs (less than 1\%).

The proportions of $\mathrm{Hg}$ and $\mathrm{Pb}$ above the mixed pollution level increased by $\sim 3 \%$. The $\mathrm{HHH}$ featured the largest increase in mixed-level $\mathrm{Hg}$ contamination, followed by the $\mathrm{SN}(1.0 \%)$. However, the increases in severe pollution were higher in the SC $(0.9 \%)$ and CJ (1.6\%) than in the NGPRs (0). Increases in Pb were observed only in the SGPRs (7\%).

There was a greater variability in the $\mathrm{Ni}, \mathrm{Cu}$, and $\mathrm{Zn}$ samples from the SGPRs that had with concentrations higher than the mixed pollution level compared to those from the NGPRs. The increases in Ni measurements above the mixed pollution level were higher in the SC and CJ (38.6\% and 6.4\%) than in the NGPRs (less than $5.0 \%$ ). $\mathrm{Cu}$ increased most in the SGPRs, with a growth of $12.0 \%$, but increased less than $5.0 \%$ in the NGPRs. At the mixed pollution level, $\mathrm{Zn}$ increased most (by 9.7\%) in the CJ, followed by the $\mathrm{HHH}(6.2 \%)$ and other regions (where increases were less than 3.0\%). There were no variations in the number of severe pollution samples from the FMGPRs; serious $\mathrm{Zn}$ pollution also remained unchanged in all regions.

The variations in As and Cr were slightly higher in the SGPRs than in the NGPRs. The percentages of seriously polluted As samples increased by $0.5-1.4 \%$ in the SGPRs but only by $0-0.2 \%$ in the NGPRs. However, the SC, CJ, and $\mathrm{HHH}$ featured similar variations $(1.4 \%)$ in mixed-level pollution. $\mathrm{Cr}$ contamination decreased most $(-4.8 \%$ overall) in the CJ, followed by the NGPRs $(-1.9 \%)$.

Overall, the increases in severe Cd pollution and mixed-level Hg pollution were larger in the NGPRs than in the SGPRs. The variations in $\mathrm{Pb}, \mathrm{Cu}$, and $\mathrm{Ni}$ at the mixed pollution level were larger in the SGPRs than in the NGPRs. The SC showed the largest increases in $\mathrm{Cd}, \mathrm{As}$, and $\mathrm{Ni}$ at the mixed and severe pollution levels. Meanwhile, the $\mathrm{CJ}$ featured the largest increases in $\mathrm{Pb}, \mathrm{Cu}$, and $\mathrm{Zn}$; $\mathrm{Pb}, \mathrm{Hg}, \mathrm{Ni}, \mathrm{Zn}$, and $\mathrm{Cu}$ increased by $3.0-8.1 \%$ and Cd increased most, by $21.5 \%$.

Comparison with the other studies of China. This study found that $21.5 \%$ of the agricultural soils in the FMGPRs were excessively polluted; this figure is slightly higher than the results of nationwide surveys conducted in 2014, which found that $19.4 \%$ of agricultural soils were contaminated with PTEs ${ }^{35,60}$. The proportions of slight, moderate, and severe pollution found in this study were $14.0 \%, 2.5 \%$, and $5.0 \%$; these are similar to those found in the national report $(13.3 \%, 2.8 \% \text {, and } 2.9 \%)^{60}$. These slight differences may have arisen from the fact that the official sampling method was uniform sampling, while the sampling points in this study were randomly distributed and some of the data from the literature may have contained publication biases such as focusing on soils surrounding mining or industrial areas. This could have increased the overall levels of elevated PTE measured in the FMGPRs. If the "Soil Environment Quality Soil Pollution Risk Control Standards" (GB 15618-2018) is used as the basis for assessment, the PTEs' content of cultivated soil in the five major grain-producing areas exceeds the risk screening value by $20.1 \%$. The risk of PTEs pollution in cultivated soils in the southern main producing areas (about 30.4-33.6\%) is heavier than that in the north (1.7-11.1\%). This trend is also consistent with the old standards and nationwide surveys. At the same time, in the future, we will also choose a variety of risk indicators from the perspective of risk, such as "Soil Environment Quality Soil Pollution Risk Management and Control Standards (Trial)" (GB 15618-2018), potential ecological risk index, health risk index, etc, to systematically assess soil PTEs pollution risk levels.

Both our research and the national report show clear increases in the total concentrations of several PTEs in agricultural soil from the 1980 s to the present. The increasing PTE concentrations trends in cultivated soils from the FMGPRs, determined using the IDW method, were consistent with those found using the point-scale method, indicating that our results are relatively reliable. Taking the most severe pollutant, Cd, as an example, IDW interpolation shows that the proportion of soil Cd concentrations above $0.27 \mathrm{mg} \cdot \mathrm{kg}^{-1}$ increased from $0.6 \%$ to $25.5 \%$ (nearly $25 \%$ ); this is similar to the point-scale results, which show an increase from $3.0 \%$ to $24.6 \%$ (nearly 21\%) in the FMGPRs. After mastering the pollution distribution of PTEs, we may pay more attention to the input (contamination source) and output (soil-crop-human body) of PTEs in soil in the future, such as the factors affecting the distribution of PTEs, the locations of emission sources, soil-crop-human risk.

Comparison with global results. The PTE soil pollution in Chinese farmland does not appear to be the most serious case globally. Although about $20 \%$ of the samples exceed the GB15618-1995 environmental quality standard, it should be noted that Chinese soil standards are quite strict. Chinese pollution thresholds are lower than many soil quality standards worldwide, which tend to increase the proportion and severity of soils considered contaminated. This can be illustrated by the Cd data; the soil limits in China are $0.3 \mathrm{mg} \cdot \mathrm{kg}^{-1}(\mathrm{pH}<7.5)$ and $0.6 \mathrm{mg} \cdot \mathrm{kg}^{-1}(\mathrm{pH}>7.5)$, which are similar to those in Denmark and Finland $\left(0.3 \mathrm{mg} \cdot \mathrm{kg}^{-1}\right)$, but lower than in countries that adopted thresholds of 0.4 to $5 \mathrm{mg} \cdot \mathrm{kg}^{-167}$. In the UK and Taiwan, soil Cd measurements are 6.7 and 15.7 times the Chinese levels, respectively.

In addition, a comparison of median PTE values from different countries (Fig. 6) shows that the PTE concentrations in cultivated soils in China are moderate at the international level. Moreover, the concentrations of the eight PTEs studied are significantly lower than those in England and the Netherlands ${ }^{68,69}$.

The median Cd concentration in this study was $0.16 \mathrm{mg} \cdot \mathrm{kg}-1$, similar to those in Europe ${ }^{6,70}$ or other European countries (i.e., Denmark ${ }^{71}$ ), the United States ${ }^{72}$, and lower than those in the rest of the world ${ }^{73}$. The median $\mathrm{Pb}$ concentration was similar to that in the rest of the world and Ireland (both were $\sim 24.97 \mathrm{mg} \cdot \mathrm{kg}^{-1}$ ) ${ }^{73}$, slightly lower 


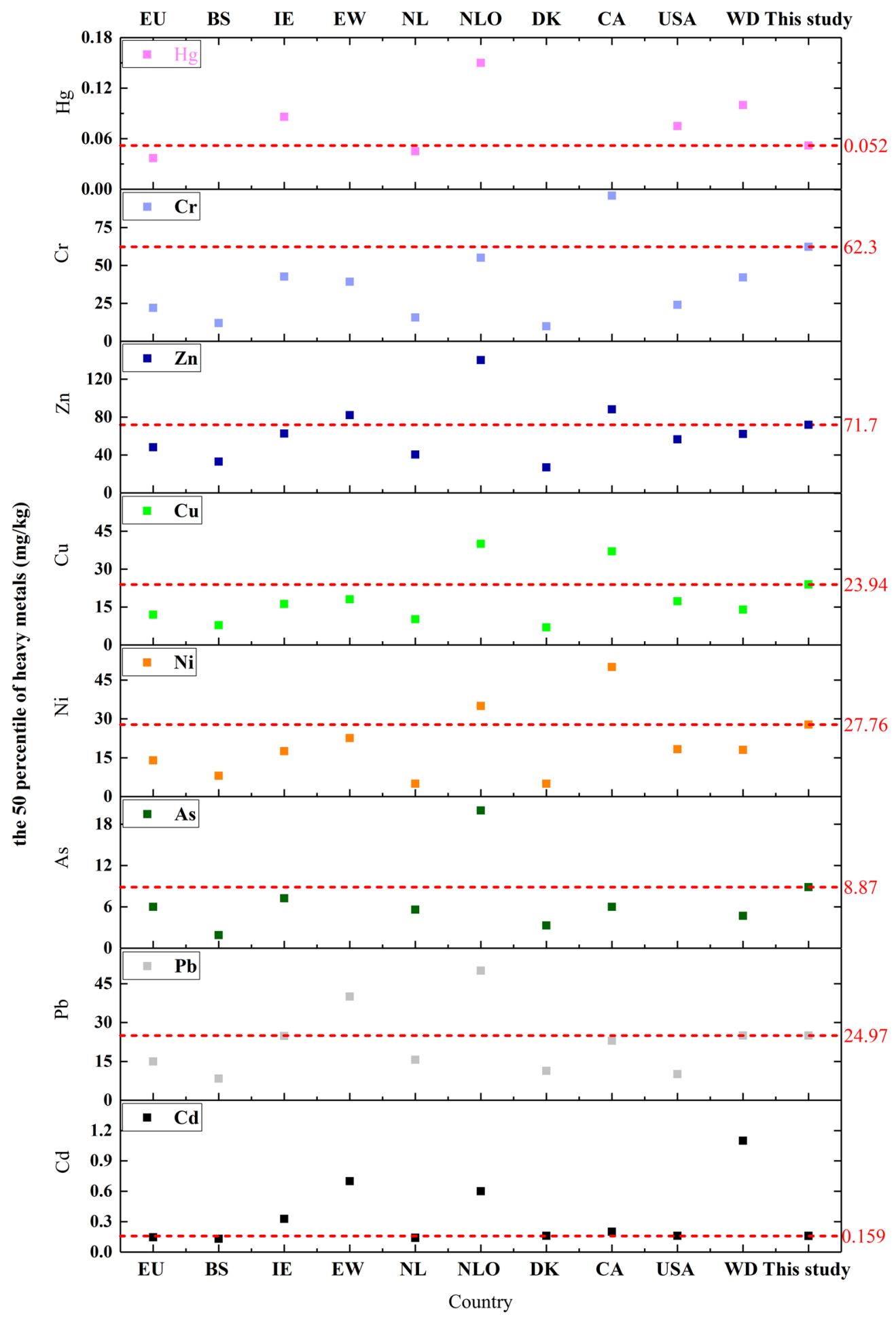

Figure 6. Comparison of the median potentially toxic trace element content in the soil around the world. The red line shows the median PTE contents examined in this study. Abbreviations: EU: Europe ${ }^{70}$; BS: Baltic states ${ }^{75}$; IE: Ireland ${ }^{73}$; EW: England ${ }^{74}$; NL: Netherlands; NLO: Netherlands official ${ }^{68}$; DK: Denmark ${ }^{71}$, CA: California ${ }^{72}$; WD: World.

than those in England ${ }^{74}$ and the Netherlands ${ }^{68}$, and slightly higher than those in other parts of Europe, the United States $^{70,72}$, and the Baltic Sea ${ }^{71,75}$. The Hg content measured in this study is also significantly lower than the median values for Ireland ${ }^{73}$ and the United States ${ }^{72}$. Ni, Cu, $\mathrm{Zn}$, and $\mathrm{Cr}$ concentrations are significantly lower than those in California ${ }^{76}$, but slightly higher than those in the Baltic Sea ${ }^{75}$ and Denmark ${ }^{71}$.

Study limitations. The data taken from the published literature may contain certain publication biases including the using following: (1) a greater number of samples from heavily contaminated areas than from 
less-contaminated areas, which may have led to higher proportions of severe pollution, (2) sites that were not uniformly distributed, which may not accurately represent the complete soil PTEs pollution scenario, (3) data from different sources and time periods, which may have introduced some uncertainty to data consistently of a good enough quality to be integrated. In this study, we used the criteria described in Section Chemical Analysis and Section Quality Control and Assurance to reduce errors.

\section{Conclusions}

The concentrations and pollution level of PTEs in agricultural soils in the FMGPRs were determined. Our results, which indicate that about $20 \%$ of soil sites are contaminated, agree well with those from the Chinese Ministry of Environmental Protection National Bulletin on Soil Pollution Status Report and provides more spatial data and information on spatiotemporal changes. Agricultural soil PTE pollution is more extensive in the SGPRs than in the NGPRs. We discuss PTE concentration trends from the 1980s to 2000s using the IDW and point-scale methods; both showed increasing trends in contaminated soil (with an increase of $19 \%$ over the study period), especially in Cd pollution which had a growth of 21-25\%. The SGPRs and HHH Plain are the key target areas for soil pollution control, which may provide some guidance on the prevention of PTE contamination and the protection of soils in high-risk areas in China in the future.

\section{Data availability}

All data generated or analyzed during this study are included in this published article (and its Supplementary Information files).

Received: 18 October 2018; Accepted: 24 November 2019; Published online: 19 December 2019

\section{References}

1. Hooda, P. S. Trace Elements in Soils. (Wiley-Blackwell, (2010).

2. Wang, C., Yang, Z. F., Zhong, C. \& Ji, J. F. Temporal-spatial variation and source apportionment of soil heavy metals in the representative river-alluviation depositional system. Environ Pollut 216, 18-26 (2016).

3. Shaheen, S. M., Shams, M. S., Khalifa, M. R., El-Dali, M. A. \& Rinklebe, J. Various soil amendments and environmental wastes affect the (im)mobilization and phytoavailability of potentially toxic elements in a sewage effluent irrigated sandy soil. Ecotoxicology and Environmental Safety 142,375-387, https://doi.org/10.1016/j.ecoenv.2017.04.026 (2017).

4. Kim, S. C. et al. Effect of chemical amendments on remediation of potentially toxic trace elements (PTEs) and soil quality improvement in paddy fields. Environmental Geochemistry and Health 39, 345-352 (2017)

5. Kelepertzis, E. Accumulation of heavy metals in agricultural soils of Mediterranean: Insights from Argolida basin, Peloponnese, Greece. Geoderma 221-222, 82-90, https://doi.org/10.1016/j.geoderma.2014.01.007 (2014).

6. Toth, G., Hermann, T., Da Silva, M. R. \& Montanarella, L. Heavy metals in agricultural soils of the European Union with implications for food safety. Environment International 88, 299-309, https://doi.org/10.1016/j.envint.2015.12.017 (2016).

7. Guagliardi, I. et al. Studying potentially toxic trace elements in soil-plant system: A case study of an olive orchard in southern Italy (Calabria). Rendiconti Online Societa Geologica Italiana 38, 59-61, https://doi.org/10.3301/ROL.2016.17 (2016).

8. Sanjeevani, U. K. P. S., Indraratne, S. P., Weerasooriya, R., Vitharana, U. W. A. \& Kumaragamage, D. Identifying the Sources and Contamination Status of Potentially Toxic Trace Elements in Agricultural Soils. Communications in Soil Science and Plant Analysis 48, 865-877 (2017)

9. Guagliardi, I., Buttafuoco, G., Cicchella, D. \& De Rosa, R. A multivariate approach for anomaly separation of potentially toxic trace elements in urban and peri-urban soils: an application in a southern Italy area. Journal of Soils and Sediments 13,117-128 (2013).

10. Antoniadis, V., Golia, E. E., Shaheen, S. M. \& Rinklebe, J. Bioavailability and health risk assessment of potentially toxic elements in Thriasio Plain, near Athens, Greece. Environmental Geochemistry and Health 39, 319-330, https://doi.org/10.1007/s10653-0169882-5 (2017).

11. Antoniadis, V. et al. Bioavailability and risk assessment of potentially toxic elements in garden edible vegetables and soils around a highly contaminated former mining area in Germany. Journal of Environmental Management 186, 192-200, https://doi. org/10.1016/j.jenvman.2016.04.036 (2017).

12. Bigalke, M., Ulrich, A., Rehmus, A. \& Keller, A. Accumulation of cadmium and uranium in arable soils in Switzerland. Environ Pollut 221, 85-93 (2017).

13. Alexakis, D. Human health risk assessment associated with $\mathrm{Co}, \mathrm{Cr}, \mathrm{Mn}, \mathrm{Ni}$ and $\mathrm{V}$ contents in agricultural soils from a Mediterranean site. Archives of Agronomy and Soil Science 62, 359-373, https://doi.org/10.1080/03650340.2015.1062088 (2016).

14. Zhou, H. et al. Accumulation of heavy metals in vegetable species planted in contaminated soils and the health risk assessment. International journal of environmental research and public health 13, 289 (2016).

15. Yuan, Z. et al. Potentially toxic trace element contamination, sources, and pollution assessment in farmlands, Bijie City, southwestern China. Environmental Monitoring and Assessment 189 (2017).

16. Li, Y. J. et al. Potentially Toxic Elements and Health Risk Assessment in Farmland Systems around High-Concentrated Arsenic Coal Mining in Xingren, China. J. Chem. 2198176, 1-10 (2018).

17. Wang, M. E., Liu, R., Chen, W. P., Peng, C. \& Markert, B. Effects of urbanization on heavy metal accumulation in surface soils, Beijing. Journal of Environmental Sciences 64, 328-334 (2018).

18. Li, Y. et al. Analysis of Historical Sources of Heavy Metals in Lake Taihu Based on the Positive Matrix Factorization Model. International journal of environmental research and public health 15, https://doi.org/10.3390/ijerph15071540 (2018).

19. Guagliardi, I., Cicchella, D., De Rosa, R. \& Buttafuoco, G. Assessment of lead pollution in topsoils of a southern Italy area: Analysis of urban and peri-urban environment. Journal of Environmental Sciences 33, 179-187 (2015).

20. Rahman, M. A., Rahman, M. M., Reichman, S. M., Lim, R. P. \& Naidu, R. Heavy metals in Australian grown and imported rice and vegetables on sale in Australia: health hazard. Ecotoxicology and environmental safety 100, 53-60 (2014).

21. Ji, X. H., Liu, S. H., Juan, H., Bocharnikova, E. A. \& Matichenkov, V. V. Effect of silicon fertilizers on cadmium in rice (Oryza sativa) tissue at tillering stage. Environmental Science and Pollution Research 24, 10740-10748 (2017).

22. Minari, G. D. et al. Agricultural management of an Oxisol affects accumulation of heavy metals. Chemosphere 185, 344-350 (2017).

23. Cozza, V. et al. 52-57.

24. Zhou, C. C., Liu, G. J., Fang, T., Wu, D. \& Lam, P. K. S. Partitioning and transformation behavior of toxic elements during circulated fluidized bed combustion of coal gangue. Fuel 135, 1-8, https://doi.org/10.1016/j.fuel.2014.06.034 (2014).

25. Niu, L., Yang, F., Xu, C., Yang, H. \& Liu, W. Status of metal accumulation in farmland soils across China: from distribution to risk assessment. Environ Pollut 176, 55-62, https://doi.org/10.1016/j.envpol.2013.01.019 (2013). 
26. Zhang, X. M., Zhang, X. Y., Zhong, T. Y. \& Jiang, H. Spatial Distribution and Accumulation of Heavy Metal in Arable Land Soil of China(in Chinese). Environmental science 25, 692-703 (2014).

27. Ma, L., Wang, L., Tang, J. \& Yang, Z. Arsenic speciation and heavy metal distribution in polished rice grown in Guangdong Province, Southern China. Food Chem. 233, 110-116, https://doi.org/10.1016/j.foodchem.2017.04.097 (2017).

28. Facchinelli, A., Sacchi, E. \& Mallen, L. Multivariate statistical and GIS-based approach to identify heavy metal sources in soils. Environ Pollut 114, 313-324, https://doi.org/10.1016/S0269-7491(00)00243-8 (2001).

29. Zhang, W., You, M. \& Hu, Y. The distribution and accumulation characteristics of heavy metals in soil and plant from Huainan coalfield, China. Environ. Prog. Sustain. Energy 35, 1098-1104, https://doi.org/10.1002/ep.12336 (2016).

30. Yang, Q. Q. et al. A review of soil heavy metal pollution from industrial and agricultural regions in China: Pollution and risk assessment. Science of the Total Environment 642, 690-700 (2018).

31. Yu, L., Cheng, J. M., Zhan, J. C. \& Jiang, A. X. Environmental quality and sources of heavy metals in the topsoil based on multivariate statistical analyses: a case study in Laiwu City, Shandong Province, China. Natural Hazards 81, 1435-1445, https://doi.org/10.1007/ s11069-015-2130-y (2016).

32. Sun, C. Y., Liu, J. S., Wang, Y., Sun, L. Q. \& Yu, H. W. Multivariate and geostatistical analyses of the spatial distribution and sources of heavy metals in agricultural soil in Dehui, Northeast China. Chemosphere 92, 517-523, https://doi.org/10.1016/j. chemosphere.2013.02.063 (2013).

33. Fan, Y., Zhu, T., Li, M., He, J. \& Huang, R. Heavy Metal Contamination in Soil and Brown Rice and Human Health Risk Assessment near Three Mining Areas in Central China. Journal of Healthcare Engineering 4124302, 1-9, https://doi.org/10.1155/2017/4124302 (2017).

34. Liu, G. N., Wang, J., Zhang, E. X., Hou, J. \& Liu, X. H. Heavy metal speciation and risk assessment in dry land and paddy soils near mining areas at Southern China. Environmental Science and Pollution Research 23, 8709-8720 (2016).

35. Zhao, F. J., Ma, Y. B., Zhu, Y. G., Tang, Z. \& McGrath, S. P. Soil Contamination in China: Current Status and Mitigation Strategies. Environmental Science \& Technology 49, 750-759, https://doi.org/10.1021/es5047099 (2015).

36. Chen, H., Teng, Y., Lu, S., Wang, Y. \& Wang, J. Contamination features and health risk of soil heavy metals in China. Science of the Total Environment 512, 143-153, https://doi.org/10.1016/j.scitotenv.2015.01.025 (2015).

37. Duan, Q. N., Lee, J. C., Liu, Y. S., Chen, H. \& Hu, H. Y. Distribution of Heavy Metal Pollution in Surface Soil Samples in China: A Graphical Review. Bulletin of Environmental Contamination and Toxicology 97, 303-309, https://doi.org/10.1007/s00128-016-18579 (2016).

38. Kang, L. \& Zhang, H. Q. Comprehensive research on the state of agricultural drought in five main grain producing areas in China. Chinese Journal of Eco-Agriculture 22, 928-937 (2014).

39. Zhou, J., Feng, K., Pei, Z. P. \& Lu, M. J. Pollution assessment and spatial variation of soil heavy metals in Lixia River Region of Eastern China. Journal of Soils and Sediments 16, 748-755, https://doi.org/10.1007/s11368-015-1289-x (2016).

40. Shao, D. W., Zhan, Y., Zhou, W. J. \& Zhu, L. Z. Current status and temporal trend of heavy metals in farmland soil of the Yangtze River Delta Region: Field survey and meta-analysis. Environ Pollut 219, 329-336 (2016).

41. Liang, J. et al. Spatial distribution and source identification of heavy metals in surface soils in a typical coal mine city, Lianyuan, China. Environ Pollut 225, 681-690 (2017).

42. Yang, Y., Christakos, G., Guo, M. W., Xiao, L. \& Huang, W. Space-time quantitative source apportionment of soil heavy metal concentration increments. Environ Pollut 223, 560-566 (2017).

43. Zhang, J. J., Wang, Y., Liu, J. S., Liu, Q. \& Zhou, Q. H. Multivariate and geostatistical analyses of the sources and spatial distribution of heavy metals in agricultural soil in Gongzhuling, Northeast China. Journal of Soils and Sediments 16, 634-644, https://doi. org/10.1007/s11368-015-1225-0 (2016).

44. Karim, Z., Qureshi, B. A., Mumtaz, M. \& Qureshi, S. Heavy metal content in urban. soils as an indicator of anthropogenic and natural influences on landscape of Karachi-A multivariate spatio-temporal analysis. Ecological Indicators 42, 20-31 (2014).

45. Modis, K., Vatalis, K. I. \& Sachanidis, C. Spatiotemporal risk assessment of soil pollution in a lignite mining region using a Bayesian maximum entropy (BME) approach. Int. J. Coal Geol. 112, 173-179 (2013).

46. Pathak, A. K., Kumar, R., Kumar, P. \& Yadav, S. Sources apportionment and spatio-temporal changes in metal pollution in surface and sub-surface soils of a mixed type industrial area in India. Journal of Geochemical Exploration 159, 169-177 (2015).

47. Long, Q., Wang, J. Y. \& Da, L. J. Assessing the Spatial-Temporal Variations of Heavy Metals in Farmland Soil of Shanghai, China. Fresenius Environmental Bulletin 22, 928-938 (2013).

48. Lu, A. X. et al. Annual Variability and Characteristics Analysis of Heavy Metals in Agricultural Soil of Beijing. Scientia Agricultura Sinica 44, 3778-3789 (2011).

49. Yang, C. F. et al. Spatial and temporal distributions of sulfur species in paddy soils affected by acid mine drainage in Dabaoshan sulfide mining area, South China. Geoderma 281, 21-29 (2016).

50. Song, Q. J. et al. Spatio-temporal Variability of Heavy Metal Concentrations in Soil-rice System and Its Socio-environmental Analysis. International Journal of Agriculture and Biology 18, 403-411 (2016).

51. Hao, C. M. Research on heavy metal pollution and evolution in farmland soil of Pinghu city, Zhejiang province, China Agricultural University (Beijing), (2010).

52. Muralikrishna, I. V. \& Manickam, V. In Environmental Management (eds Iyyanki V. Muralikrishna \& Valli Manickam) 135-152 (Butterworth-Heinemann, (2017)

53. Zheng, C. J. The Atlas of Soil Environmental Background Values in the People's Republic of China. (China Environmental Science Press, 1994).

54. Lu, R. K. Methods of soil and agricultural chemistry analysis. (Chinese Agricultural Science and Technology Press, (2000).

55. Wei, B. G. \& Yang, L. S. A review of heavy metal contaminations in urban soils, urban road dusts and agricultural soils from China. Microchem J. 94, 99-107, https://doi.org/10.1016/j.microc.2009.09.014 (2010).

56. Cheng, H. X. et al. Overview of trace metals in the urban soil of 31 metropolises in China. Journal of Geochemical Exploration 139, 31-52 (2014).

57. Lee, C. S., Li, X. D., Shi, W. Z., Cheung, S. C. \& Thornton, I. Metal contamination in urban, suburban, and country park soils of Hong Kong: A study based on GIS and multivariate statistics. Science of the Total Environment 356, 45-61 (2006).

58. Zhu, G. X., Guo, Q. J., Xiao, H. Y., Chen, T. B. \& Yang, J. Multivariate statistical and lead isotopic analyses approach to identify heavy metal sources in topsoil from the industrial zone of Beijing Capital Iron and Steel Factory. Environmental Science and Pollution Research 24, 14877-14888 (2017).

59. Chinese Environmental Protection Administration (CEPA). (Beijing, (1995).

60. Ministry of Environmental Protection and Ministry of Land and Resources. National Soil Pollution Status Survey Bulletin, $<$ http:// www.zhb.gov.cn/gkml/hbb/qt/201404/t20140417_270670.html> (2014-04-27).

61. Song, W., Chen, B. \& Liu, L. Soil Heavy Metal Pollution of Cultivated Land in China. Research of Soil and Water Conservation 20, 293-298 (2013)

62. Chen, T. B. et al. Assessment of heavy metal pollution in surface soils of urban parks in Beijing, China. Chemosphere 60, 542-551 (2005).

63. Zou, J., Liu, X., Dai, W. \& Luan, Y. Pollution assessment of heavy metal accumulation in the farmland soils of Beijing's suburbs. Environmental Science and Pollution Research, 1-10, https://doi.org/10.1007/s11356-018-2708-5 (2018). 
64. Liang, S. X., Li, X. Y., Xu, H., Wang, X. \& Gao, N. Spatial-Based Assessment of Heavy Metal Contamination in Agricultural Soils Surrounding a Non-ferrous Metal Smelting Zone. Bulletin of Environmental Contamination and Toxicology 91, 526-532, https://doi. org/10.1007/s00128-013-1110-8 (2013).

65. Reimann, C. \& Garrett, R. G. Geochemical background - Concept and reality. Science of the Total Environment 350, 12-27, https:// doi.org/10.1016/j.scitotenv.2005.01.047 (2005).

66. Wilding, L. P. In Proceedings of the soil spatial variability. (ed. Bouma, J.) 166-187 (Wageningen) (1985).

67. Chen, N. C., Zheng, Y. J., He, X. F., Li, X. F. \& Zhang, X. X. Analysis of the report on the national general survey of soil contamination. Journal of Agro-Environment Science 36, 1689-1692 (2017).

68. Breward, N. Arsenic and presumed resistate trace element geochemistry of the Lincolnshire (UK) sedimentary ironstones, as revealed by a regional geochemical survey using soil, water and stream sediment sampling. Applied Geochemistry 22, 1970-1993 (2007).

69. Nicholson, F. A., Smith, S. R., Alloway, B. J., Carlton-Smith, C. \& Chambers, B. J. An inventory of heavy metals inputs to agricultural soils in England and Wales. Science of The Total Environment 311, 205-219, https://doi.org/10.1016/S0048-9697(03)00139-6 (2003).

70. Salminen, R. Foregs geochemical atlas of Europe, EuroGeoSurveys. (2005-01).

71. Bak, J., Jensen, J., Larsen, M. M., Pritzl, G. \& Scott-Fordsmand, J. A heavy metal monitoring-programme in Denmark. Science of the Total Environment 207, 179-186 (1997).

72. Burt, R., Wilson, M. A., Mays, M. D. \& Lee, C. W. Major and trace elements of selected pedons in the USA. Journal of Environmental Quality 32, 2109-2121 (2003).

73. Zhang, C. S., Fay, D., McGrath, D., Grennan, E. \& Carton, O. T. Statistical analyses of geochemical variables in soils of Ireland. Geoderma 146, 378-390 (2008).

74. McGrath, S. P. \& Loveland, P. J. The soil geochemical atlas of England and Wales. (Blackie Academic \& Professional, (1992).

75. Reimann, C. et al. Agricultural Soils in Northern Europe. (Schweizerbart, (2003).

76. Goldhaber, M. B. et al. A regional soil and sediment geochemical study in northern California. Applied Geochemistry 24, 1482-1499 (2009).

\section{Acknowledgements}

This work was supported by the Strategic Priority Research Program of the Chinese Academy of Sciences (No. XDA20040201) and the Chinese Academy of Engineering Consulting Research Project (No. 2016-ZD-10-2). We will also thank constructive comments from editors and the reviewers.

\section{Author contributions}

Statistical Analysis, E.S.; Writing-Original Draft Preparation, E.S; Sampling, E.S., C.H., E.X.; and WritingReview and Editing, E.X., H.Z.

\section{Competing interests}

The authors declare no competing interests.

\section{Additional information}

Supplementary information is available for this paper at https://doi.org/10.1038/s41598-019-55278-5.

Correspondence and requests for materials should be addressed to E.X. or H.Z.

Reprints and permissions information is available at www.nature.com/reprints.

Publisher's note Springer Nature remains neutral with regard to jurisdictional claims in published maps and institutional affiliations.

(c) (i) Open Access This article is licensed under a Creative Commons Attribution 4.0 International License, which permits use, sharing, adaptation, distribution and reproduction in any medium or format, as long as you give appropriate credit to the original author(s) and the source, provide a link to the Creative Commons license, and indicate if changes were made. The images or other third party material in this article are included in the article's Creative Commons license, unless indicated otherwise in a credit line to the material. If material is not included in the article's Creative Commons license and your intended use is not permitted by statutory regulation or exceeds the permitted use, you will need to obtain permission directly from the copyright holder. To view a copy of this license, visit http://creativecommons.org/licenses/by/4.0/.

(C) The Author(s) 2019 